\title{
Model DSS Penentuan Produk Berdasarkan Preferensi Konsumen dengan Analisis Konjoin
}

\author{
Feri Prasetyo ${ }^{1}$, Agus Dendi Rachmatsyah ${ }^{2 *}$, Wahyu Tisno Atmojo ${ }^{3}$ \\ ${ }^{1}$ Program Studi Sistem Informasi Akuntansi, Universitas Bina Sarana Informatika, Jakarta \\ ${ }^{2}$ Program Studi Sistem Informasi, Institut Sains dan Bisnis Atma Luhur, Kepulauan Bangka Belitung \\ ${ }^{3}$ Program Studi Sistem Informasi, Universitas Pradita, Banten \\ Indonesia \\ feri.fpo@bsi.ac.id, dendi@atmaluhur.ac.id, wahyu.tisno@pradita.ac.id
}

\begin{abstract}
Decision making as a stage of a particular action process (among many alternatives) which is primarily the end goal of some choice goal. There will be a choice of conditions when the desired system does not meet the agreed target, the procedure does not approach the predicted perfect result or the object does not go according to plan. This study aims to identify maximally the ingredients that affect the use of shampoo products. Determine the user's perception and behavior in using shampoo that can be used as a benchmark for the success of a product that is in great demand. To find out how the respondent's perception of an object consisting of one or several product designs for Decision Making. The hope is that voters can develop personal preferences from the choice of a product, determine which products are preferred by consumers, determine the combination of the main attributes that are most preferred by consumers for the existing segments. Decisions can be made based on the results of the respondent's stimulation, namely products that are grammatically useful, good quality, easy to buy, medium, moisturizer (sunscreen), affordable prices, very fragrant, and small $30 \mathrm{ml}$ bottles. Respondent's opinion greatly influences Conjoint analysis. The better the data is ranked and there is no similarity in the data, the better the results. From here we can extract value, significance and correlation.
\end{abstract}

\section{Keywords: Decision Making Systems, Conjoint Analysis, Complexity}

ABSTRAK - Pengambilan keputusan dikategorikan sebagai tahap proses penentuan suatu tindakan tertentu (di antara banyak alternatif) yang titik utamanya adalah tujuan akhir dari beberapa tujuan pilihan. Akan ada pilihan kondisi ketika sistem yang diinginkan tidak memenuhi target yang disepakati, prosedur tidak mendekati hasil sempurna yang diprediksi atau objek tidak berjalan sesuai rencana. Penelitian ini dimaksudkan untuk mengidentifikasi secara maksimal konten yang mempengaruhi alasan penggunaan produk sampo. Menentukan persepsi dan pengukuran perilaku pengguna dalam menggunakan merek sampo yang dapat dijadikan ukuran keberhasilan suatu produk yang banyak diminati. Untuk dapat mengetahui bagaimana persepsi responden terhadap suatu objek yang terdiri dari satu atau beberapa desain produk untuk Pengambilan Keputusan. Harapannya, pemilih dapat mengembangkan preferensi pribadi dari pilihannya terhadap suatu produk, menentukan produk mana yang disukai konsumen, menentukan kombinasi atribut utama yang paling disukai konsumen untuk segmen yang ada. Sebuah keputusan dapat diambil berdasarkan hasil stimulasi responden yaitu produk yang manfaatnya mudah pada tata bahasa, kualitas baik, mudah dibeli, medium, mengandung moisturizer (tabir surya), harga terjangkau, wangi sangat harum, dan botol kecil $30 \mathrm{ml}$. Pendapat responden sangat mempengaruhi perhitungan analisis Konjoin. Semakin baik data pada peringkat dan tidak ada kesamaan dalam data, semakin baik hasilnya. Dari sini kita dapat mengekstrak interpretasi nilai, signifikansi, dan korelasi.

\section{Kata Kunci: Sistem Pengambilan Keputusan, Analisis Konjoin, Kompleksitas}

\section{PENDAHULUAN}

Dalam kehidupan banyak sekali kendala yang dialami oleh setiap manusia, baik fisik maupun mental, fisik lebih menekankan pada tubuh manusia itu sendiri salah satunya adalah rambut dimana rambut merupakan mahkota bagi setiap orang. Rambut adalah bagian terpenting dari penampilan. Bagi seorang wanita, rambut kepala yang berupa helaian yang jumlahnya ribuan dikatakan sebagai bagian sentra tubuh, mempermanis penampilan diatas dan juga bisa dianggap sebagai bingkai dan ciri khas wajah. Dari rambut bisa dilihat bentuk kecantikannya, rambut sangat menunjang penampilan seseorang bahkan penampilan seseorang secara keseluruhan. Dalam model kecantikan dan make-up, wanita rela meluangkan waktu untuk melakukan perawatan rambut dan menata rambutnya [1].

Banyak orang melakukan hal-hal untuk memanjakan rambut mereka, seperti sampo dan creambat, tetapi di sinilah banyak masalah muncul, tidak hanya dari rambut itu sendiri tetapi dari bahan dan produk yang digunakan untuk merawat rambut. Dimana shampoo sendiri akan menghasilkan busa dalam proses menghilangkan kotoran kulit, kemampuan busa yang dihasilkan mengontaminasi 
rambut [2]. Banyak orang berpikir bahwa membersihkan rambut atau keramas itu mudah. Masalah dalam membersihkan rambut terletak pada cocok atau tidaknya produk sampo untuk jenis rambut itu sendiri dan efek sampingnya. Sampo sendiri sebenarnya bisa dibuat dengan menggunakan bahan-bahan alami seperti ekstrak daun kembang sepatu yang mengandung fenol, saponin dan flavonoid [3]. Ada banyak produk unggulan yang menawarkan keistimewaan untuk perawatan rambut, salah satunya adalah sampo. Salah satu penyebab kurang percaya diri dan membatasi aktivitas seseorang di luar ruangan adalah karena memiliki keluhan rambut berketombe [4].

Shampoo merupakan deterjen pembersih bagi rambut, pada kenyataanya apakah shampoo dari produk tersebut cocok dengan kondisi kulit kepala ataukah mengalami efek samping yang lain serta perlu di telusuri bahwa setiap orang berbeda pengunaan shampoonya. Selain itu dapat diambil kesimpulan shampoo mana yang berkualitas untuk rambut. Sudah dapat diprediksi bahwa dari kegiatan ini jawaban tersebut setiap individu pasti akan berbeda. Dan merk shampoo pun akan berbeda pula. Karena banyak sekali produsen sampo yang menawarkan produknya ke konsumen. Produk unggulannya, mulai dari anti ketombe, anti panas matahari, anti rontok, bahkan lebih panjang, dan lebih tebal, serta mudah dipasang dan tidak mudah rusak. Salah satu langkah yang dilakukan perusahaan adalah dengan memperkuat nama merek (branding) dari produknya [5].

Dalam hal ini diperlukan suatu kegiatan bagaimana menemukan suatu keputusan, dimana keputusan tersebut merupakan suatu kegiatan yang menghasilkan suatu saran [6], untuk memilih suatu produk khususnya shampoo untuk rambut. Sebagai langkah awal, tidak ada salahnya sebelum membeli produk sampo, sebaiknya kenali dulu kondisi dan jenis rambut. Setelah mengetahui jenis rambut, akan lebih mudah untuk memilih sampo yang tepat.

Berdasarkan permasalahan tersebut, Analisis Konjoin digunakan untuk membantu dalam pengambilan keputusan. Cara ini sering disebut multivariat, pengembangannya dapat membantu menciptakan aliran kombinasi dan elemen komponen suatu produk baru atau produk lama yang digemari konsumen. Conjoint Analysis dalam banyak hal diterapkan dalam proses pemasaran, terutama inti dari desain pengembangan produk yang paling disukai konsumen dalam hal memaksimalkan preferensi konsumen. Penelitian ini hanya sebagai model untuk pengambilan keputusan. Conjoint Analysis dapat memprediksi nilai preferensi konsep dari pengguna produk dengan membangkitkan rangsangan sehingga dapat dirangking dan dirancang, tahapan pertimbangan konflik dalam Conjoint Analysis akan mengarahkan konsumen untuk mengurutkan atribut-atribut rangsangan tersebut. Memaksimalkan penilaian yang paling disukai konsumen terhadap atribut-atribut faktor yang dianggap mewakili pilihan.

Sebelumnya, Analisis Konjoin digunakan oleh Aulele [7] dalam penelitiannya bahwa Program Studi Statistika akan memiliki jumlah dosen yang cukup, ruang kuliah yang lebih sedikit, peminat program studi yang banyak, kondisi laboratorium yang baik, kondisi perpustakaan yang baik dan pengguna lulusan yang banyak. Menurut penilaian dosen FMIPA, urutan kepentingan atribut yang perlu diperhatikan dalam pembukaan prodi statistika adalah jumlah dosen sebagai prioritas utama, disusul atribut pengguna lulusan, ruang kuliah, perpustakaan, peminat program studi, dan laboratorium.

Dalam penelitian Matdoan; unsur dominan yang sangat berpengaruh pada proses memotivasi belajar mahasiswa dalam kelas yang utama merupakan kegiatan interaksi dosen dengan mahasiswa value presentase mendapatkan $21,09 \%$. Unsur berikutnya dilihat dari jenis kelamin dosen dijadikan atribut yang pilihanya kurang penting oleh responden dengan ukuran presentase sebanyak 10,75\%. Berikutnya perolehan hasil dari proses kegunaan/utilitas nilai tiap taraf atribut menunjukkan dimana atribut paling berpengaruh pada proses memotivasi semangat belajar mahasiswa didapat dosen yang memiliki jenis kelamin laki-laki, kemudian berkarakter santai, memiliki penampilan modis, mempunyai latar belakang pendidikan sarjana, ditambah memberikan tugas yang cukup, lalu berikutnya metode pembelajaran inkonvensional serta proses dari kegiatanya tatap muka banyak melakukan interaksi dengan mahasiswa [8].

Pada penelitian Situmorang didapatkan perolehan hasil kajian, kombinasi tingkat atribut yang digemari mahasiswa pada alur memilih Simcard GSM adalah tarif beban biaya SMS paketan, biaya panggilan per menit, paket akses internet full $4 \mathrm{G}$, sinyal kuat dan bonus SMS. Atribut yang menjadi pilihan utama mahasiswa dalam memilih kartu prabayar GSM adalah paket internet. Nilai bobot kepentingan relatif dari atribut paket internet lebih besar dibandingkan dengan atribut lainnya yaitu sebesar $0,352[9]$.

\section{METODOLOGI}

\section{A. Metode Penelitian}

Tahapan Penelitian menggunakan alur pendekatan pada kegiatan Explanatory yaitu dengan melakukan carian unsur faktor atribut lalu dijadikan stimuli pertimbangan yang berisi proses dari pembuktian. Kemudian dibangun dan mencari teori yang sepadan melalui studi kepustakaan dengan penambahan pendekatan mengunakan metode Analisis Konjoin. Setelah itu diuji menggunakan aplikasi Statistical Package for the Social Sciences (SPSS).

\section{B. Populasi dan Sampel Penelitian}

Populasi pengguna kali ini difokuskan pada beberapa pengguna sampo di wilayah Bekasi dan sekitarnya untuk mempermudah pencarian responden dengan mengunjungi pusat perbelanjaan. Adapun pengunjung pusat perbelanjaan di kawasan Kota Bekasi meliputi 3 pusat perbelanjaan, 20 responden untuk Metropolitan Mall, 20 responden untuk Mega Bekasi, dan 20 responden untuk Cikarang Commercial Center. Sebanyak 60 kuesioner memberikan preferensi terhadap 18 stimulus 
dan memberikan rating atau rangking yang dianggap terbaik adalah shampoo merek Sunsilk.

\section{HASIL DAN PEMBAHASAN}

\section{A. Responden}

Responden yang diberikan kuisioner berjumlah 60 yaitu pelanggan pengguna produk sampo Sunsilk yang berkunjung ke pusat perbelanjaan di kawasan Bekasi yang terdiri dari 20 responden dari Metropolitan Mall, 20 responden dari Mega Mall Bekasi, dan 20 responden dari Cikarang Commercial Center. Kuesioner disebarkan langsung kepada responden dengan mengisi kuesioner. Dengan menanyakan terlebih dahulu apakah shampoo yang digunakan merek Sunsilk atau bukan, jika iya maka dilanjutkan dengan mengisi stimuli. Data profil responden yang menjadi objek penelitian dapat dilihat pada Tabel 1 berikut:

Tabel 1. Klasifikasi Responden

\begin{tabular}{clrr}
\hline \multirow{2}{*}{ No } & Lokasi Pengambilan Sample & $\begin{array}{r}\text { Jumlah Responden } \\
\text { Pria (orang) }\end{array}$ & $\begin{array}{r}\text { Jumlah Responden } \\
\text { Wanita (orang) }\end{array}$ \\
\hline 1 & Mall Metropolitan Bekasi & 4 & 16 \\
2 & Mega Mall & 2 & 18 \\
3 & Cikarang Comercial Center & 2 & 18 \\
\hline \multicolumn{2}{r}{ Total Responden } & 8 & 52 \\
\hline
\end{tabular}

Tahapan proses Analisis Konjoin pada tools sintak editor di program SPSS di proses dengan menentukan tahapan model yaitu: a) Membuat stimuli untuk memaksimalkan kirnerja Orthogonal; b) Melakukan proses Konjoin dengan prosedur Konjoin.

\section{B. Gambaran Stimuli}

Stimuli dimaksudkan sebagai perpaduan 2 konsep antara faktor dengan level tingkatan. Produk pembersih rambut dalam hipotesis dapat didesain dengan model memilih 1 level dari beberapa ketentuan disetiap unsur elemennya. Proses ini terdapat 7 atribut elemen (faktor) dan 3 nilai tingkatan, maka dapat dibuat perpaduan pilihan produk pernyataan sebanyak 18 dengan rumus:

$$
\begin{aligned}
& \text { Minimum Profil }= \\
& \text { Total Level dari Semua Faktor }- \text { Jumlah Faktor }+1
\end{aligned}
$$

Tujuh faktor yang digunakan dilihat dari (1) manfaat produk, (2) kualitas produk, (3) kemudahan dalam membeli, (4) kandungan yang terdapat dalam produk, (5) harga produk, (6) tingkat kewangian produk, dan (7) bentuk kemasan; untuk mendesain stimulasi (kombinasi antara faktor dengan level).

Membuat stimuli dalam Analisis Konjoin dengan SPSS antara lain sebagai berikut:
ORTHOPLAN

/FACTORS=

MANFAAT 'Manfaat' ('Menghilangkan Ketombe' 'Mudah

Ditata' 'Menghilangkan Ketombe')

KUALITAS 'Kualitas' ('Kurang' 'Standart' 'Baik')

KEMUDAHAN MEMBELI 'Kemudaban Membeli'

('Mudah Didapat' 'Sedang' 'Sulit didapat')

KANDUNGAN 'Kandungan'

('Vitamin' 'Moisturize' 'Conditioner')

HARGA 'Harga'

('Murab' 'Terjangkau' 'Mabal')

KEWANGLAN 'Kewangian'

('Kurang' 'Relatif' 'Sangat Wangi')

BENTUK KEMASAN 'Kemasan'

('90ml' '180ml' '350ml')

$/$ HOLDOUT $=O$.

SAVE OUTFLLE $=$ 'CONJOINT.SAV'.

Factors merupakan atribut yang akan dibuat stimuli, dalam kasus ini berjumlah 7 dengan skala ordinal dimana pada variabel ini responden akan memilih sangat diminati, diminati, atau tidak diminati. Orthoplan adalah pembuat stimuli. Holdout merupakan pengujian hasil dengan di beri nilai 0. Save Outfile digunakan untuk menyimpan file

\begin{tabular}{|c|c|c|c|c|c|c|c|c|c|}
\hline \multicolumn{10}{|c|}{ 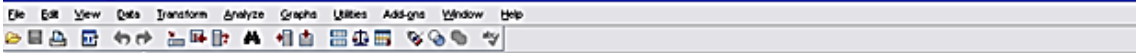 } \\
\hline \multicolumn{10}{|c|}{ 25: newertas } \\
\hline & MANFAAT & MUAUTAS & KEMLOAHAN_MEMBEU & KANDUNGAN & HARGA & KEWANGLAN & BENTUK_KEMASAN & STATUS_ & CARD_ \\
\hline 1 & 30 & 300 & 10 & $1 . \infty$ & 200 & 200 & 200 & 0 & 1 \\
\hline 2 & 100 & $1 . \infty$ & 100 & 100 & 100 & 100 & 100 & 0 & 2 \\
\hline 3 & $3 \infty$ & 200 & 100 & 300 & 100 & 100 & 300 & 0 & 3 \\
\hline 4 & 200 & 100 & 100 & 200 & 300 & 200 & 300 & 0 & 4 \\
\hline 5 & 300 & 1.00 & 200 & 200 & 300 & 1.00 & 200 & 0 & 5 \\
\hline 6 & 10 & 300 & 200 & 200 & 100 & 200 & 100 & 0 & 6 \\
\hline 7 & 200 & $3 \infty$ & 100 & 300 & 300 & 300 & 100 & 0 & 7 \\
\hline 8 & 300 & $2 \infty$ & 200 & 1.00 & 300 & 300 & 100 & 0 & 8 \\
\hline 9 & 100 & 100 & 200 & 300 & 200 & 300 & 300 & 0 & 9 \\
\hline 10 & 10 & 200 & 300 & 1.00 & 300 & 200 & 300 & 0 & 10 \\
\hline 11 & 300 & 300 & 300 & 200 & 100 & 300 & 300 & 0 & 11 \\
\hline 12 & 200 & 1.00 & 300 & 1.00 & 100 & 300 & 200 & 0 & 12 \\
\hline 13 & 100 & $3 \infty 0$ & 300 & 300 & 300 & 100 & 200 & 0 & 13 \\
\hline 14 & 300 & 1.00 & 300 & 300 & 200 & 200 & 100 & 0 & 14 \\
\hline 15 & 200 & 200 & 300 & 200 & 200 & 1.00 & 100 & 0 & 15 \\
\hline 16 & 100 & 200 & 100 & 200 & 200 & 300 & 200 & 0 & 16 \\
\hline 17 & 200 & 200 & 200 & 300 & 100 & 200 & 200 & 0 & 17 \\
\hline 18 & 200 & 3.00 & 200 & 1.00 & 200 & 1.00 & 300 & 0 & 18 \\
\hline$\frac{19}{19}$ & & & & & & & & & \\
\hline
\end{tabular}
dengan nama "conjoint.sav".

Gambar 1. Statistik Data Editor Setiap Stimuli 


\section{Melakukan Conjoint dengan SPSS}

Dalam hal ini karena ada 18 stimuli, maka kepada responden diminta memberikan pendapat atas ke 18 stimuli dengan cara melakukan peringkat persepsi di setiap preferensi dengan memberi kode simbol angka yaitu 1 = paling disukai, 18 = kurang disukai. Pendapat setiap responden ini disebut sebagai utility.

Tahapan pengolahan persepsi dalam stimuli untuk proses Conjoint perlu tuliskan kode khusus yang tidak dilakukan lewat interface tampilan program, tetapi lewat penulisan peritah dan eksekusi script di Syntax Editor. Dimana data responden dimasukan terlebih dahulu kedalam editor. Oleh sebab itu dapat dituliskan pada Editor dalam SPSS sebagai berikut:

\section{DATA LIST FREE/ QN PROD1 TO PROD18.}

BEGIN DATA.

$<$ masukan data responden $>$

END DATA.

CONJOINT PLAN='SUNSILK.SAV'

/FACTORS=

MANFAAT 'Manfaat' ('Menghilangkan Ketombe' 'Mudah

Ditata' 'Mencegab Kerontokan')

KUALITAS 'Kualitas' ('Kurang' 'Standart' 'Baik')

\author{
KEMUDAHAN_MEMBELI 'Kemudahan Membeli' \\ ('Mudah Didapat' 'Sedang' 'Sulit didapat') \\ KANDUNGAN 'Kandungan' \\ ('Vitamin' 'Moisturize' 'Conditioner') \\ HARGA 'Harga'('Murah' 'Terjangkau' 'Mahal') \\ KEWANGLAN 'Kewangian' \\ ('Kurang' 'Relatif' 'Sangat Wangi') \\ BENTUK_KEMASAN 'Kemasan' \\ ('90 ml' '180 ml' '350ml') \\ / SCORE =PROD1 PROD2 PROD3 PROD4 PROD5 \\ PROD6 PROD7 PROD8 PROD9 PROD10 PROD11 \\ PROD12 PROD13 PROD14 PROD15 PROD16 \\ PROD17 PROD18 \\ /UTILITY='SUNSILK_1_UTILITY.SAV'.
}

\section{Hasil Pengujian}

Hasil Pengujian didapat setelah mengkonversi semua data responden dan menghubungkan ke syntak stimuli yang telah dibuat. Dari hasil generate diatas akan menghasilkan Model Description. Berdasarkan Table 2 dari Orthoplan Conjoint dengan menggunakan SPSS dijelaskan bahwa faktor Manfaat, Kualitas, Kemudahan Membeli, Kandungan, Harga, Kewangian, Bentuk Kemasan yang semuanya memiliki 3 level.

Tabel 2. Model Description

\begin{tabular}{rlrl}
\hline No & Factors & Nof Levels & Relation to Ranks or Scores \\
\hline 1 & MANFAAT & 3 & Discrete \\
2 & KUALITAS & 3 & Discrete \\
3 & KEMUDAHAN_MEMBELI & 3 & Discrete \\
4 & KANDUNGAN & 3 & Discrete \\
5 & HARGA & 3 & Discrete \\
6 & KEWANGIAN & 3 & Discrete \\
7 & BENTUK_KEMASAN & 3 & Discrete \\
\hline
\end{tabular}

\section{E. Utilities}

Utilities dapat diartikan sebagai file pelengkap atau file feedback dari alur desain Conjoint, komponen isian pengolahan hitungan utility diambil dari prosedur pilihan setiap responden dari hasil proses generate diatas akan menghasil persentase dari beberapa faktor yang sudah ditentukan seperti pada Tabel 3.

Tabel 3. Utilities

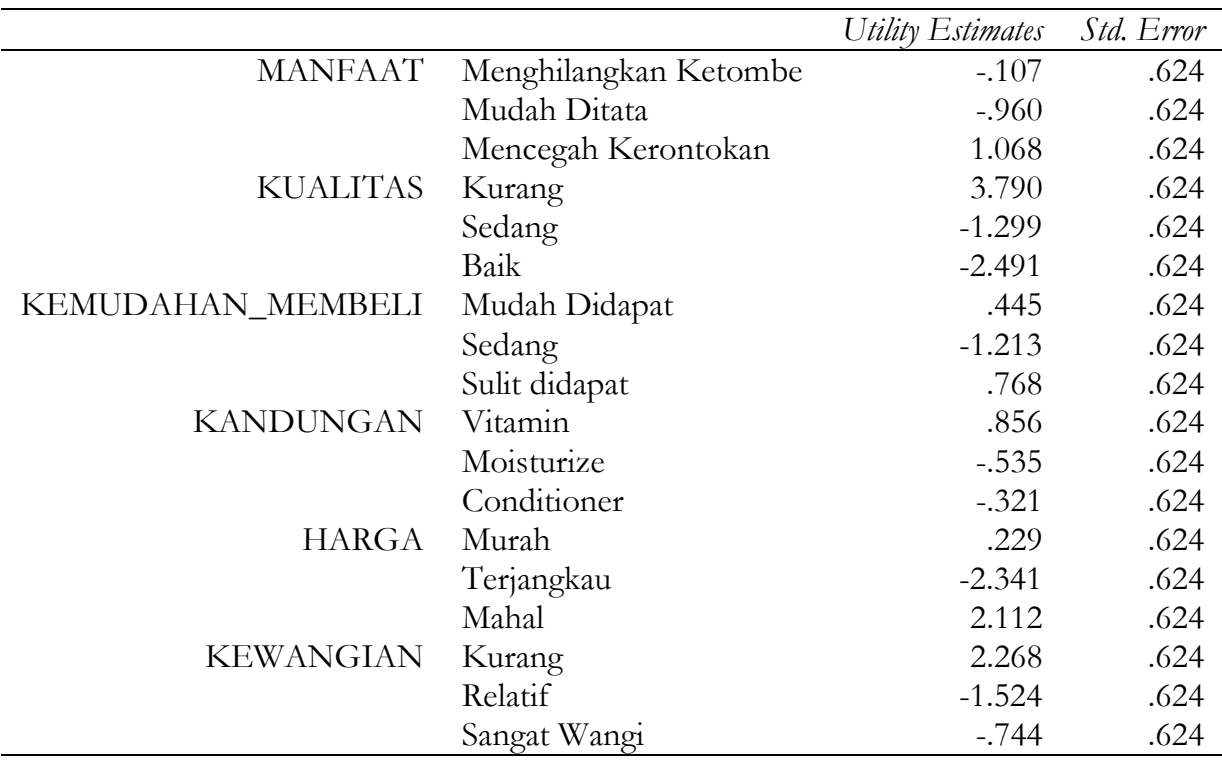




\begin{tabular}{rrrrr}
\hline & & & Utility Estimates & Std. Error \\
\hline BENTUK_KEMASAN & $90 \mathrm{ml}$ & -.330 & .624 \\
& $180 \mathrm{ml}$ & -1.044 & .624 \\
& $350 \mathrm{ml}$ & 1.373 & .624 \\
\hline & & CONSTANT & 9.477 & .442 \\
\hline
\end{tabular}

Berdasarkan interpretasi dari Table 3 disimpulkan bahwa dari data sebanyak 60 responden dengan rata-rata 9.447. Nilai minus menunjukan bahwa responden banyak lebih menyukai faktor tersebut. Dengan prediksi perkiraan stimuli 1 sampai dengan 18 menyatakan stimuli yang dihasilkan dan dibagi jumlah total stimuli sehingga faktor yang dapat ditentukan berdasarkan stimuli tersebut menyatakan:

a. Interpretasi Manfaat; bahwa dilihat dari segi Manfaat yaitu Faktor produk yang paling banyak diminati adalah "Mudah Ditata" -0.960

b. Interpretasi Kualitas; bahwa dilihat dari segi Kualitas yaitu produk yang paling banyak diminati adalah "Kualitas Baik" - 2.49

c. Interpretasi Kemudahan Membeli; bahwa dilihat dari segi Kemudahan Membeli yaitu produk yang paling banyak diminati adalah "Sedang" - 1.213 d. Interpretasi Kandungan; bahwa dilihat dari segi Kandungan yaitu produk yang paling banyak diminati adalah "Mousturizer" -0.353

e. Interpretasi Harga; bahwa dilihat dari segi Harga yaitu produk yang paling banyak diminati adalah "Terjangkau" -2.341

f. Interpretasi Kewangian; bahwa dilihat dari segi Kewangian yaitu produk yang paling banyak diminati adalah "Sangat wangi" - 0.744

g. Interpretasi Bentuk Kemasan adalah bentuk kemasan $180 \mathrm{ml}$. Kemasan yaitu produk yang paling banyak diminati adalah "180ml" -1.044.

Berdasarkan hasil yang didapat sesuai dengan kerangka konsep yang dibuat, dapat diambil keputusan bahwa berdasarkan hasil dari preferensi yang telah di generate dengan orthoplan menggunakan SPSS syntak editor dari proses conjoint.

Tabel 4. Importance V alues

\begin{tabular}{rlr}
\hline No & Factors Importance & Importance Value \\
\hline 1 & MANFAAT & 9.076 \\
2 & KUALITAS & 28.111 \\
3 & KEMUDAHAN_MEMBELI & 8.865 \\
4 & KANDUNGAN & 6.229 \\
5 & HARGA & 19.930 \\
6 & KEWANGIAN & 16.971 \\
7 & BENTUK_KEMASAN & 10.817 \\
\hline
\end{tabular}

Dari perhitungan Faktor Importance ini dapat diketahui bahwa dari kriteria yang dipilih berdasarkan stimuli yang didapat dari 60 responden memilih suatu produk Shampoo yang paling terpenting berdasarkan peringkat tertinggi (1) Kualitas 28.111, (2) Harga 19.930, (3) Kewangian 16.971, (4) Bentuk Kemasan 10.817, (5) Manfaat 9.076, (6) Kemudahan Membeli 8.865, (7) Kandungan 6.229.

Dari gambaran model tersebut berdasarkan keputusan konsumen hasil dari "kualitas" menduduki posisi paling diminati.

\section{F. Model Pengambilan Keputusan}

Berdasarkan hasil dari proses Conjoint dapat disimpulkan bahwa implementasi model keputusan yang dapat diambil dari preferensi produk shampoo seperti Gambar 2

\section{1) Intelligence Phase}

Proses dimana terjadi untuk menentukan beberapa kegiatan dengan memberikan penjelasan beberapa produk yang sudah di produksi dan digunakan oleh konsumen dengan dengan menganalisa beberapa hal antara lain: (a) Menentukan masalah, antara lain dengan mencari masalah apa yang dihadapi dari pengguna produk tersebut. (b) Klasifikasi masalah, antara lain dengan mengkotak-kotakan kegiatan berdasarkan faktor yang saling mempengaruhi. (c) Penguraian masalah, menjelaskan secara spesifik dari beberapa faktor masalah yang terjadi. (d) Kepemilikan masalah, menspesifikan dimana biasanya masalah ini terjadi.

\section{2) Design Phase}

Rancangan dari proses olahan tahapan phase meliputi pembuatan, proses pengembangan dan analisis hal-hal yang kemungkinan akan dilakukan pemilih, penerapan untuk pemahaman pemecahan masalah yang akan terjadi ditambah lagi adanya pengecekan solusi untuk memdapat kelayakan. Juga nantinya akan mendapatkan solusi model baru dari pemecahan masalahnya yang didesain, dites dan divalidasi. Antara lain (a) Komponen elemen rancangan, (b) Struktur model desain, (c) Seleksi prinsip pemilihan (kriteria evaluasi), (d) Pengembangan (penyediaan alternatif), (e) Perkiraan hasil perhitungan, (f) Pengukuran hasil, (g) Skenario.

\section{3) The Choice Phase}

Tahap ini menjelaskan beberapa pilihan membuat beberapa criteria untuk membuat pernyataan konsumen 
pengguna produk dengan penggabungan beberapa stimuli yang sudah ditentukan.

4) Critical Success Factor (CSF)

Critical Success Factor (CSF) untuk mengindentifikasi faktor yang kritis terhadap pencapaian tujuan organisasi dan terbentuknya produk shampoo baru.

5) Implementation
Harapan selanjutnya menjalani hasil yang telah di peroleh pada tahap CSF dimana persepsi yang sudah diolah menjadi sebuah desain inovasi baru di jalankan untuk dapat mencari hasil sebagai solusi untuk masalah yang terjadi produk baru yang diharapkan sesuai dengan keinginan penguna dapat di bentuk yaitu dengan menciptakan produk shampoo baru sesuai permintaan konsumen.

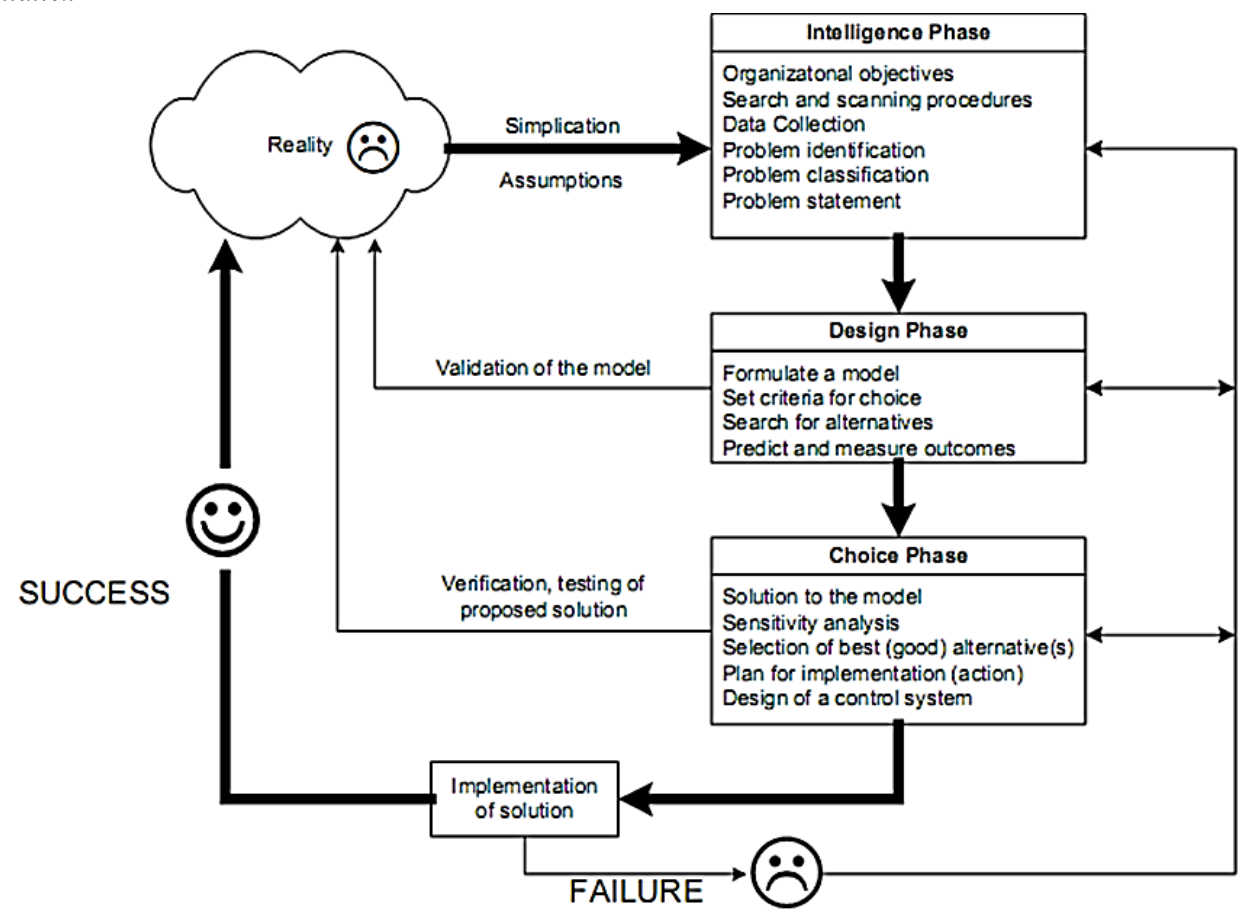

Gambar 2. Model Pengambilan Keputusan [10]

\section{KESIMPULAN}

Setelah melakukan rekapan dan perhitungan prosedur pengujian yang dilakukan dari inputan hipotesis dan masalah yang diterima, didapatkan simpulan bahwa:

1) Faktor-faktor yang didapat dalam penelitian terdiri dari 7 faktor yaitu manfaatnya, kualitas, kemudahan membeli, kandungan shampoo, harga, kewangian, dan bentuk kemasan. Mendesain stimulasi (kombinasi antara faktor dengan level), serta 18 stimuli dari stimulasi yang ada, dengan melakukan proses Conjoint mengguanakan SPSS.

2) Hasil Keputusan yang dapat diambil berdasarkan olahan pilihan peringkat, dan stimuli pemilih yaitu produk yang dilihat dari faktor manfaatnya dimana mudah ditata, kualitas yang baik, kemudahan membeli sedang, kandungan mengandung mousturizer (tabir surya), harga terjangkau, kewangian sangat wangi, dan bentuk kemasan botol kecil $30 \mathrm{ml}$.

3) Pendapat responden sangat mempengaruhi hasil perhitungan dari proses tersebut yang paling dominan adalah konsumen melihat suatu produk berdasasrkan kualitas. Didapat dari 60 responden dengan persepsi Kualitas $28.111 \%$.

\section{SARAN}

1) Aspek Manajerial; untuk para produsen shampoo Sunsilk pengambilan keputusan amatlah penting dalam membuat suatu produk unggulan, diharapkan dalam pengambilan keputusan menciptakan sebuah produk baru sebelum dibuat produk tersebut hendaknya diriset terlebih dahulu agar sesuai dengan preferensi dari konsumen pemakainya shampoo jenis apa yang di butuhkan konsumen.

2) Aspek Sistem; diharapkan dalam penelitian explorasi selanjutnya bila menggunakan topik bahasan yang sama agar dibuatkan suatu sistem pengambilan keputusan dengan menggunakan database untuk mengambil keputusan, sehingga hasilnya dapat diketahui dengan jelas.

3) Aspek Penelitian Lanjutan; dalam merangking pendapat responden, diharapkan untuk membuat pertanyaan yang mudah dimengerti serta jumlah dan faktornya lebih banyak, karena faktor tersebut akan mempengaruhi produk yang akan di produksi atau dipasarkan dikemudian hari. 


\section{DAFTAR PUSTAKA}

[1] G. C. Tasya C. Malonda, Paulina V. Y. Yamlean, "Formulasi Sediaan Sampo Antiketombe Ekstrak Daun Pacar Air (Impatiens Balsaminal.) dan Uji Aktivitasnya Terhadap Jamur Candidaalbicansatcc 10231 Secara In Vitro," Pharmacon, vol. 6, no. Farmasi, pp. 97-109, 2017.

[2] T. Sayuti, N. A, Winarso, A, Lestari, "Formulasi Gel Dan Mikroemulsi Penumbuh Rambut Kombinasi Ekstrak Ethanol Daun Waru (Hibiscus Tiliaceus L.) dan Buah Asam (Tamarindus Indica L.)," J. Terpadu Ilmu Kesehat., vol. 4, no. Ilmu Kesehatan, pp. 82-196, 2015.

[3] W. T. Setyowati Uliah, Marwiyah, "Efektivitas Daun Waru Sebagai Bahan Dasar ShampooDaun Waru Untuk Mengurangi Rambut Rontok," Teknobunga, vol. 7, no. Jurnal Teknologi Busana dan boga, pp. 74-78, 2019.

[4] B. A. Mahataranti, N., I.Y, Astuti, "Formulasi Shampoo Antiketombe Ekstrak Etanol Seledri (Apium Graveolens L.) dan Aktivitasnya Terhadap Jamur Pityrosporum ovale," J. Pharm., vol. 9, no. Pharmacy, pp. 128-138, 2012.

[5] Kurniawan Antonius Philipus, "Analisis Keterlibatan Konsumen Terhadap Produk Shampoo Berdasarkan Faktor Pembeli (Studi Kasus Pada Mahasiswa S1 Manajemen Universitas Nusa Nipamaumere)," J. Projemen, vol. 6, no. Manajemen, pp. 42-64, 2019.
[6] R. E. Kurniawan Didik, Anie Rose Irawati, "ImplementasiSistemPengambil Keputusan Pada Sistem Rekam Medis Pribadi,” J. Komputasi, vol. 3, p. 110, 2015.

[7] M. W. T. Aulele Salmon N., Helda Y. Taihuttu, "Penerapan Analisis Konjoin Dalam Penilaian Dosenfmipa Terhadap Pembukaan Program Studi Statistika Di Universitas Pattimura," J. Ilmu Mat. Dan Terap., vol. 12, pp. 093 - 098, 2018.

[8] A. Z. W. Matdoan M.Y., ImanuelY. Rupilu, Y. ALesnussa, "Analisis Konjoin untuk Menentukan Persepsi Mahasiswa Matematika terhadap Dosen," Jambura J. Math., vol. 1, pp. 79-88, 2019.

[9] P. I. Situmorang Tridoni Roy, Yuni arti Desi, "Penerapan Metode Full-profile Dalam Pengumpulan Data Untuk Analisis Konjoin (Studi Kasus: Preferensi Mahasiswa Universitas Mulawarman Terhadap Kartu Prabayar GSM)," J. Eksponensial, vol. 9, pp. 169-176, 2018.

[10] Efraim Turban, Decision Support and Expert Systems: Management Support Systems, 4th ed. United States of America: Prentice-Hall, 1995. 